\title{
lluminação e segurança pública: uma investigação sobre a relação entre design e criminalidade urbana pela perspectiva feminina
}

\section{Street lighting and public safety: an investigation on design and urban fear of crime through women's perspective}

\author{
Victória Loureiro Cardoso, UEMG. \\ vloureirocar@gmail.com
}

Sílvia de Alencar Rennó, UEMG.

silvia.renno@uemg.br

\section{Resumo}

Este estudo investiga a contribuição do espaço urbano e da iluminação pública na construção da percepção de segurança das mulheres em pontos de ônibus de uma cidade brasileira. Apresentam-se três etapas de investigação e seus respectivos resultados: (1) aplicação de questionários online para verificar as percepções dos indivíduos sobre os pontos de ônibus de cidades brasileiras; (2) seleção e análise de quatro pontos da região central de Belo Horizonte, Minas Gerais; (3) realização de formulários in loco nos pontos investigados, entrevistando mulheres usuárias do transporte público. Os resultados da investigação buscam discutir formas de viabilizar um planejamento urbano que contribua para o acesso igualitário às cidades.

Palavras-chave: Iluminação, Percepção de Segurança, Espaços Públicos.

\begin{abstract}
This study investigates the contribution of urban space and public lighting on women's perceived safety at bus stops of a Brazilian city. A three step method investigation and their results are presented: (1) online questionnaires about individual perceptions of Brazilian bus stops; (2) selection and analysis of four bus stops in downtown Belo Horizonte, in Minas Gerais; (3) an in loco form to interview women users of public transport on the investigated bus stops. Research results seek to discuss ways of facilitating an urban planning that contributes to the equal access to the city.
\end{abstract}

Keywords: Lighting, Perceived Safety, Public Space. 


\section{Introdução}

A violência e o medo estão presentes na vida urbana da mulher afetando, sobretudo, sua mobilidade. Mulheres que possuem uma relação de insegurança com a cidade em que vivem têm seu direito de ir e vir limitado pelo medo. Isto é, a sensação e a percepção de insegurança podem afetar a ocupação do espaço público. Limitação dos horários nas ruas, desvios de caminhos e desistências de deslocamento são alguns exemplos. Questiona-se, assim, qual a contribuição do espaço na construção da percepção de segurança das mulheres no contexto de violência urbana.

Este artigo propõe identificar fatores ambientais que possam contribuir com um planejamento urbano que preserve e promova o direito da mulher à cidade, concentrando sua abordagem na investigação sobre a relevância da iluminação no contexto de segurança pública. Pretende-se analisar em que medida a iluminação urbana estaria relacionada à sensação de segurança das mulheres, considerando a realidade brasileira.

Para isso, realizou-se uma investigação em pontos de ônibus, local onde as mulheres se sentem mais vulneráveis nas cidades (ITDP, 2018). Foram selecionados quatro pontos na região central de Belo Horizonte, Minas Gerais, por esta ser uma zona de grande trânsito de pessoas e confluência de linhas de ônibus. A análise do Sistema de Indicadores, divulgado em 2010 pelo Movimento Nossa $\mathrm{BH}^{1}$, demonstra que a região central possui elevadas taxas de estupro e agressão às mulheres, sendo 37,67 casos de tentativa e consumação por cem mil habitantes. A complexidade e a pluralidade das circunstâncias espaciais dos locais dos pontos também foram consideradas, visando a variabilidade da pesquisa, assim como a grande rotatividade ou presença de pessoas, permitindo a aplicação de formulários in loco.

\section{Metodologia}

O estudo, de natureza qualitativa e quantitativa, iniciou-se com uma revisão bibliográfica de publicações científicas referentes à iluminação pública, percepção espacial e criminalidade. Considerando verificar a discussão proposta no contexto brasileiro, utilizaram-se instrumentos de pesquisa que permitissem analisar tanto os aspectos físicos quanto a percepção dos indivíduos.

Um questionário online foi elaborado objetivando verificar se usuários de ônibus, homens e mulheres, sentem-se inseguros no espaço dos pontos, e investigar os motivos dessa possível insegurança. As perguntas foram elaboradas apoiadas em dados e informações obtidos na revisão bibliográfica.

Seguidamente, realizou-se uma pesquisa de campo, baseada na observação participante, com registros fotográficos nos locais de estudo, permitindo identificar fatores possivelmente desfavoráveis à sensação de segurança em cada local. Estes fatores foram estabelecidos como positivos e negativos, baseados nas teorias de Espaço Defensível (Defensible Space Theory) (NEWMAN, 1972, apud PERKINS et al., 1993), Janela-quebrada (Broken-window Theory)

1 Coletivo independente formado por cidadãos de Belo Horizonte. 
(WILSON; KELLING, 1982) e Prospecto-refúgio (Prospect-refuge) (FISHER; NASAR, 1992). Dentre os positivos estão a presença de estabelecimentos que criem fluxo de pessoas e oportunidades de vigilância; proximidade de postos policiais; estruturas de abrigo; proteção contra intempéries; presença de câmeras de segurança. Como fatores negativos estão a presença de obstáculos naturais ou artificiais que dificultam a visibilidade do entorno ou atuam como esconderijo para infratores; espaços em situação degradante ou de abandono; presença de penumbras.

Relativo à iluminação, foram observadas luminárias e lâmpadas, temperaturas de cor e integração com a vegetação. Esta análise baseou-se, também, no Manual de Distribuição de Projetos de Iluminação Pública, da Companhia Energética de Minas Gerais (2012), que estabelece critérios básicos da Norma de Distribuição 3.4 para projetos de iluminação urbana.

Objetivando constatar a relação entre espaço físico e percepção de segurança das mulheres, realizaram-se formulários in loco com usuárias de transporte público nos pontos de ônibus investigados. Suas identidades foram preservadas, não havendo registros de imagem ou qualquer identificação. Estes foram aplicados em diferentes dias da semana a partir das $18 \mathrm{~h}$, pois a maioria dos crimes de estupro nas vias públicas ocorre durante a noite e madrugada (ITDP, 2018). Os resultados obtidos com a aplicação dos instrumentos técnicos foram quantificados e apresentados graficamente.

Considera-se de extrema relevância para este estudo o diálogo com essas mulheres. Entendese que um mesmo espaço físico pode oferecer múltiplas percepções, isto é, cada indivíduo possui valores, experiências e culturas que particularizam sua relação com um determinado ambiente.

A percepção ambiental é importante porque introduz variabilidade (cultural e pessoal) e modifica a noção de um único ambiente com propriedades invariantes. Uma vez aceito que o ambiente percebido pelo usuário e suas qualidades positivas e negativas podem ser diferentes do planejador ou do designer, e que diferentes grupos de usuários podem ter diferentes ambientes percebidos, então a abordagem de entender a cidade e os critérios usados para o design deve ser diferente. (RAPOPORT, 1977, p.27).

É importante afirmar que este estudo compreende a relevância em conciliar a análise objetiva do espaço físico investigado e a análise subjetiva das percepções dos usuários. Assim, não se assume que as percepções são uma reflexão precisa da realidade.

\section{Panorama da criminalidade no espaço urbano}

No Brasil, a relação entre as mulheres e o espaço público é marcada pela violência e insegurança, evidenciadas por índices de assédio e crimes de violência sexual. Conforme a Organização Mundial da Saúde (OMS), esse tipo de violência se define por "qualquer ato sexual ou tentativa de obter ato sexual, investidas ou comentários sexuais indesejáveis, ou tráfico ou qualquer outra forma, contra a sexualidade de uma pessoa usando coerção," (KRUG et al., 2002, p.149). O assédio em espaços públicos apresenta-se por comportamentos verbais e não verbais incluindo gestos, comentários, sugestões vulgares e ameaças, vitimizando as mulheres de forma a objetificá-las (BOWMAN, 1993). 
As mulheres experimentam uma ampla variedade de experiências de vitimização em vários domínios. E, essas experiências podem levar a sentimentos de medo e/ou vulnerabilidade. Por sua vez, o medo pode ser visto como um tipo de estressor ambiental. Além disso, experimentar uma vitimização no passado pode ser estressante, assim como antecipar a possibilidade de uma vitimização no futuro. (KEANE, 1998, p.62).

Evidenciando essa cultura no Brasil, pesquisas demonstram graves taxas de violência contra mulheres no cenário urbano. Conforme pesquisa da ActionAid (2016), 86\% das mulheres entrevistadas já sofreram assédio ou violência nos espaços públicos, 57\% receberam comentários de cunho sexual e $8 \%$ foram estupradas em público. Segundo o ITDP (2018), dentre os casos de estupro reportados à polícia em 2011, aproximadamente $90 \%$ eram de vítimas mulheres e, citando dados do Instituto de Pesquisa Econômica Aplicada (IPEA), 60\% dos crimes de estupro são praticados por desconhecidos, entre 18 horas e 6 horas da manhã, sobretudo nas vias públicas.

Esse contexto de violência e vulnerabilidade pode influenciar a percepção da mulher sobre a cidade e sua relação com ela. Rapoport (1977) revela que a interação homem-ambiente envolve as áreas (1) cognitiva, que compreende a percepção sobre o ambiente; (2) afetiva, que envolve os valores e emoções sobre esse ambiente; (3) conativa, relacionada ao efeito sobre o ambiente em resposta à (1) e (2).

Logo, a relação entre a mulher e uma cidade violenta não será de bem-estar, mas possivelmente, de insegurança e medo. Acredita-se que, no cenário urbano, esses fatores estão relacionados à mobilidade da mulher e poderiam afetar o seu Direito à Cidade - direito de todo habitante ao acesso igualitário à cidade (BOER; DE VRIES, 2009). A liberdade das mulheres é "substancialmente limitada pelo assédio nas ruas, o que reduz sua mobilidade física e geográfica e, muitas vezes, impede que elas estejam sozinhas em espaços públicos." (BOWMAN, 1993, p.520).

Deve-se considerar que situações de espera pelo transporte público, quando não há possibilidade de deslocamento, podem tornar a mulher uma vítima de sua própria insegurança. A parada de ônibus é, no cenário urbano, o local onde as mulheres se sentem mais vulneráveis devido ao isolamento do local, à falta de movimento no entorno, ao tempo de espera pelo ônibus ou à ausência de iluminação ou de equipamentos de segurança (ITDP, 2018).

\section{Relações entre espaço percebido e segurança pública}

Pesquisas sobre criminologia ambiental revelam que existem características físicas do espaço que podem estar relacionadas à criminalidade. Segundo a teoria do Espaço Defensível, defendida e publicada por Newman em 1972 (PERKINS et al., 1993), fatores como iluminação, visibilidade do entorno, existência de barreiras e oportunidades de vigilância natural poderiam auxiliar na prevenção ao crime. Entende-se como vigilância natural, o patrulhamento das ruas pelo uso informal dos espaços públicos (JACOBS, 2000).

A segurança das ruas é mais eficaz, mais informal e envolve menos traços de hostilidade e desconfiança exatamente quando as pessoas as utilizam e usufruem espontaneamente e estão menos conscientes, de maneira geral, de que estão policiando. O requisito básico da vigilância é um número substancial de estabelecimentos e outros locais públicos dispostos 
ao longo das calçadas do distrito; deve haver entre eles, sobretudo estabelecimentos e espaços públicos que sejam utilizados de noite. (JACOBS, 2000, p.37).

As oportunidades de vigilância natural têm grande importância na manutenção da ordem pública. A ocupação do espaço público e, consequentemente, a criação de oportunidades de vigilância, seriam ocasionadas pela existência, por exemplo, de estabelecimentos comerciais. Estes motivariam a utilização das calçadas em que estão presentes e da região do entorno (JACOBS, 2000).

As pesquisas também demonstram uma possível relação entre comportamento e criminalidade. Segundo Perkins et al. (1993), sinais de incivilidade associados a comportamentos sociais, como embriaguez, ou às condições físicas do espaço, como a degradação, podem ser evidência de impunidade e relacionam-se à incidência de crimes urbanos. Isto também é discutido pela teoria da Janela-quebrada, popularizada por Wilson e Kelling (1982), segundo a qual, essas incivilidades são, assim como uma janela quebrada deixada sem reparos, um sinal de falta de controle social e representam a vulnerabilidade de uma comunidade, criando mais espaço para oportunidades de crimes.

Outra via de pesquisa entende que o espaço físico determina o comportamento dos indivíduos e o nível de criminalidade de determinado território. Essa ideia é confrontada por Rapoport (1977), que revela que as configurações espaciais podem inibir ou facilitar, isto é, podem catalisar um comportamento, mas não podem determiná-lo. Assim, é possível inferir que fatores ambientais influenciam a qualidade da segurança de determinado espaço e a percepção de segurança dos indivíduos, mas não impedem a ocorrência de episódios criminosos.

Um estudo de Fisher e Nasar (1992), baseado na teoria de Prospecto-refúgio² de Appleton, revela que a sensação de segurança do indivíduo é influenciada pelo grau de perspectiva (boa visibilidade do entorno e poucas barreiras físicas), refúgio (proteção) e oportunidade de escape (facilidade de encontro com outros indivíduos em situações de potencial ameaça) que um espaço oferece. Entretanto, os autores demonstram as dualidades dessas características, uma vez que um ambiente que oferece refúgio pode também favorecer o infrator em situação de crime por ser um possível esconderijo (FISHER; NASAR, 1992). Ademais, segundo Atkins et al. (1991), configurar um espaço pode contribuir para a redução da insegurança, sendo a iluminação um desses fatores.

Muitos estudos são realizados para demonstrar quais os efeitos da iluminação sobre a criminalidade e a sensação de segurança, mas poucas evidências apoiam a relação entre esses fatores. Uma investigação realizada por Atkins et al. (1991) analisou os dados de um programa de iluminação de Wandsworth, em Londres, em 1985, que possuía, em parte, o objetivo de prevenção ao crime. A análise de 3500 ruas iluminadas e 100 mil crimes reportados à polícia mostrou, após um ano, que a iluminação não afetou a taxa de criminalidade da região pesquisada, mas modificou positivamente a percepção de segurança dos indivíduos, especialmente das mulheres.

\footnotetext{
2 Jay Appleton, em 1975, publicou a teoria do Prospecto-refúgio afirmando existir uma preferência humana por espaços que possibilitam observar o entorno (perspectiva) sem o risco de ser visto (refúgio).
} 
Farrington e Welsh (2002) demonstram duas teorias principais sobre a relação entre iluminação e segurança pública. A primeira afirma que a iluminação pública poderia condicionar melhor visibilidade do entorno e ocupação do espaço, aumentando as possibilidades de vigilância sobre potenciais infratores. Loewen et al. (1993) e Haans e Kort (2012) revelam que a iluminação está relacionada à visão do entorno, possibilitando o aumento da percepção de segurança e a melhora de resposta do indivíduo sobre potenciais eventos perigosos.

A segunda teoria revela que a iluminação relaciona-se ao bem-estar. Isto é, vias bem iluminadas sugerem que determinada área não está negligenciada, incentivando o uso e controle social desses ambientes e reduzindo, assim, a insegurança dos pedestres (FARRINGTON; WELSH, 2002). Ademais, a iluminação pode ser considerada importante para a prevenção da criminalidade, mas não uma barreira ao crime.

Iluminação pública é uma alteração tangível ao ambiente, mas não constitui uma barreira física para o crime. Entretanto, ela pode atuar como um catalisador para estimular redução de crimes através da mudança em percepções, atitudes e comportamentos de residentes e potenciais infratores. (FARRINGTON; WELSH, 2002, p.11).

Estudos também sugerem que a vigilância natural seria decisiva na relação entre iluminação e segurança pública, visto que a iluminação poderia encorajar a percepção de atividades suspeitas e aumentar as oportunidades de vigilância, agindo como inibidora ao crime (ATKINS et al., 1991). Jacobs (2000) demonstra que a iluminação proporciona reconforto aos pedestres, induzindo-os a contribuir para a manutenção da segurança dos espaços públicos.

Assim, as luzes induzem essas pessoas a contribuir com seus olhos para a manutenção da rua. Além do mais, como é óbvio, a boa iluminação amplia cada par de olhos - faz com que os olhos valham mais porque seu alcance é maior. Cada par de olhos a mais e qualquer aumento em seu alcance representam um trunfo para as áreas apagadas e desvitalizadas. Porém, as luzes não têm efeito algum se não houver olhos (...). (JACOBS, 2000, p.43).

Compreende-se, também, que a presença ou ausência de pessoas nos espaços públicos, os chamados "proprietários naturais da rua", poderia influenciar na prevenção de criminalidade. Farrington e Welsh (2002) afirmam que a iluminação pode gerar um aumento de pedestres, capazes de inibir as ações de um infrator pelo risco de ser reconhecido e ter seu crime interrompido.

\section{Investigação no contexto nacional}

Os dados evidenciados pelo referencial teórico conduziram a uma investigação no contexto nacional, visando analisar a relação entre percepção de segurança e iluminação pública, composta por três instrumentos de pesquisa (questionário online; pesquisa de campo - análise espacial; formulário in loco) cujos resultados serão apresentados a seguir.

\section{Resultados do questionário online}

O questionário online, desenvolvido através da plataforma Google Formulários e compartilhado via redes sociais, teve 136 participantes de diferentes cidades brasileiras, sendo $82,4 \%$ mulheres e $17,6 \%$, homens. Participaram da segunda seção do questionário aqueles que 
responderam utilizar o ônibus como transporte público (106 indivíduos ou 77,9\% do total). Destes, $91,5 \%$ já se sentiram inseguros em situação de espera pelo ônibus, dos quais $92 \%$ são mulheres.

Os principais motivos identificados para a sensação de insegurança nesses locais foram a iluminação insuficiente e a falta de pessoas no entorno, isto é, baixo fluxo de pedestres (FIG.1). Dos respondentes que já se sentiram inseguros, aproximadamente $50 \%$ utilizam o ônibus entre 18h e 6h da manhã, quando ocorrem mais crimes de estupro nas vias (ITDP, 2018).

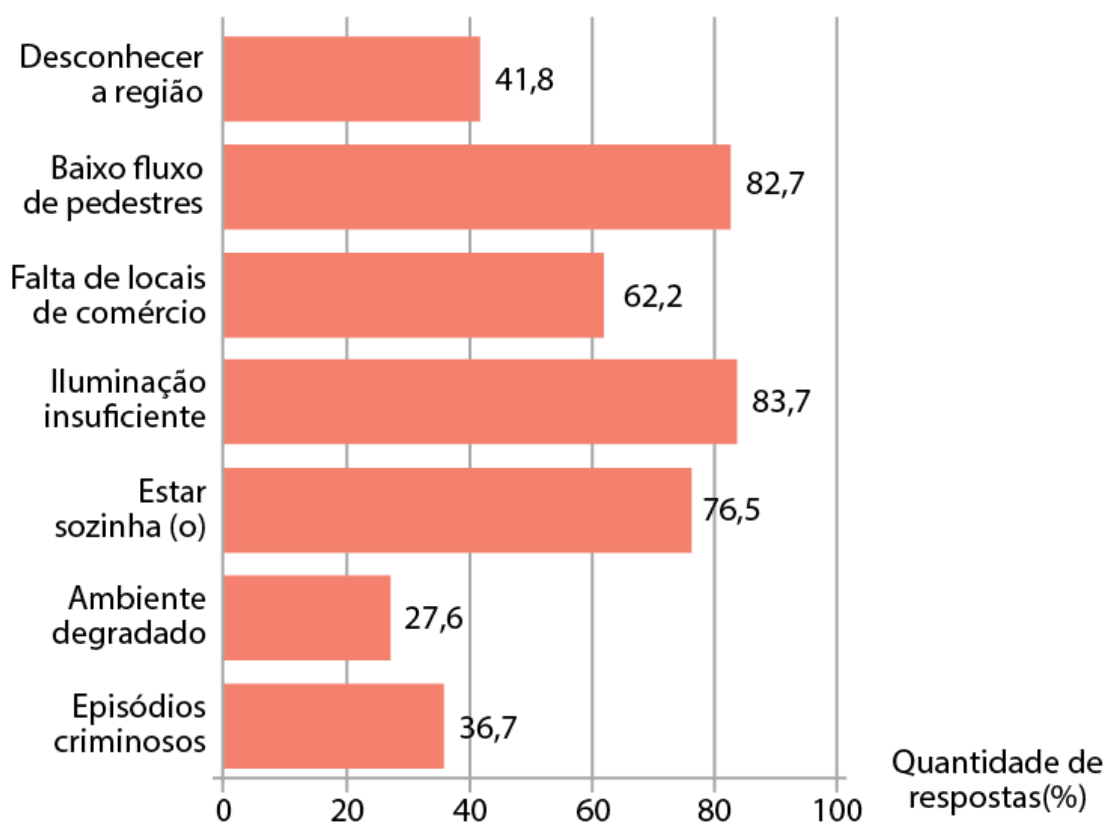

Figura 1: Motivos para insegurança revelados pelos questionários online. Fonte: As autoras.

Dos participantes, 94,3\% afirmaram que a iluminação poderia tornar um espaço mais seguro. Dentre os motivos, destacam-se que a iluminação: proporcionaria aumento da visibilidade do entorno, permitindo anteceder ameaças; inibiria infratores pelo medo da identificação, pois espaços mal iluminados facilitam o anonimato; e encorajaria as pessoas a ocuparem os espaços públicos, aumentando a sensação de segurança.

As respostas permitiram concluir que estes usuários de ônibus, majoritariamente mulheres, sentem-se recorrentemente inseguros nos pontos, o que está relacionado, principalmente, à iluminação, corroborando com a idéia de relação entre percepção de segurança e características espaciais. As informações extraídas dos questionários justificaram o prosseguimento do estudo. 


\section{Análise dos pontos de ônibus}

Os pontos de ônibus investigados neste estudo localizam-se na Rua Guaicurus, em frente ao número 244 (Ponto A); na Praça Rui Barbosa (Ponto B); na Avenida dos Andradas, em frente ao número 344 (Ponto C); e na Rua Aarão Reis, em frente ao número 496 (Ponto D).

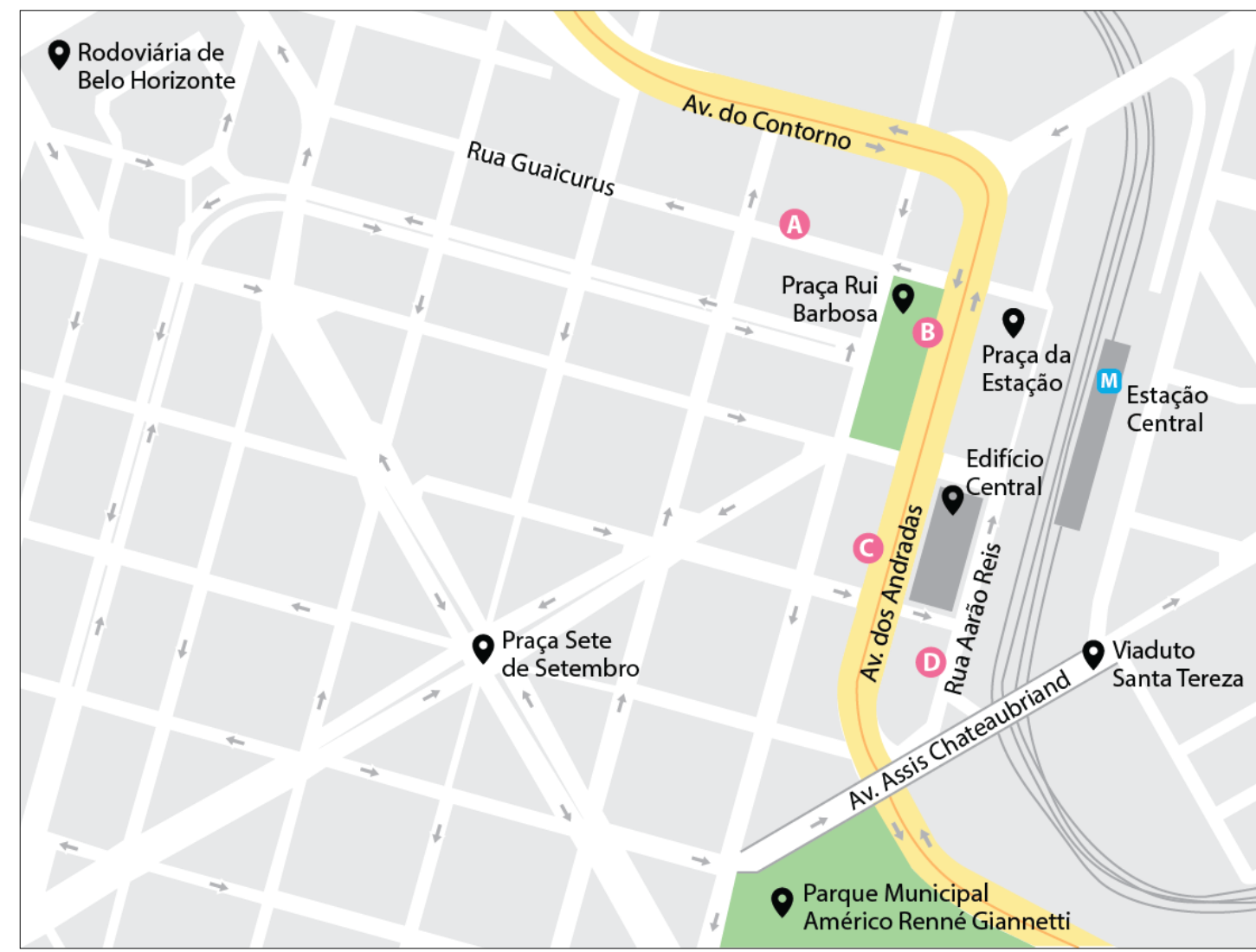

Mapa 1: Localização dos pontos de ônibus selecionados.

Fonte: Elaborado pelas autoras a partir de imagem do Google Maps.

Os pontos selecionados apresentam características bastante distintas. O Ponto A encontra-se em uma área sem comércio ou residências, mas apenas edificações ociosas. Logo, não há muitas oportunidades de vigilância natural, definida por Jacobs (2000) como "olhos na rua". Os pontos B e C localizam-se em avenida com grande quantidade de estabelecimentos comerciais, fluxos de pedestres e automóveis. Entretanto, no Ponto C, há oportunidades de vigilância natural até horários adiantados da noite pela presença de uma faculdade e bares, contribuindo com a percepção de segurança no local. Já o Ponto D localiza-se em uma rua de apenas dois quarteirões, utilizados como ponto final de ônibus e via de retorno. O fluxo de pedestres é favorecido pelo comércio da região e pela Estação Central, visto que esta rua é via de acesso ao metrô.

Observou-se a ausência de câmeras de segurança e de postos policiais próximos aos quatro pontos. Contudo, patrulhas móveis foram vistas nos pontos B, C e D e, apenas na Praça Rui Barbosa verificou-se a presença de rondas policiais até no início da madrugada. 
Os pontos também diferem quanto às características físicas. O Ponto A não possui estrutura, tornando os usuários expostos e desprotegidos contra intempéries. (FIG.2). Já o Ponto B assemelha-se a um pergolado, com cobertura vazada e arbustos nas laterais, os quais constituem barreiras físicas e visuais, levando os usuários a aguardarem os ônibus no meio-fio, em situações de risco de acidentes. (FIG.3). O Ponto C possui estrutura com assento e cobertura, mas sem fechamentos laterais e posterior, não constituindo obstáculo visual aos usuários. Entretanto, a ausência de fechamento posterior, região de baixo controle visual, aumenta a sensação de vulnerabilidade. (FIG.4) Isto também ocorre no Ponto D, o qual possui estrutura extensa, com assentos e cobertura, porém em estado degradado, não fornecendo boa proteção contra intempéries. (FIG.5)

A iluminação dos locais dos pontos ocorre, principalmente, pelas luminárias públicas da região, isto é, nenhum deles possui iluminação específica. Isto leva os usuários do Ponto A a permanecerem em uma área próxima, com maior iluminância. Entretanto, as superfícies escuras dos muros do entorno não contribuem para o iluminamento da região, pelo seu baixo coeficiente de reflexão. (FIG.2). No Ponto B, a iluminação provém das luminárias da avenida e da praça, local onde foram verificadas "zonas escuras" resultantes do posicionamento não uniforme das luminárias. (FIG.3) As luzes das calçadas e das vias iluminam os Pontos C e D. A cobertura translúcida do primeiro permite a transmissão luminosa para o interior do ponto, ainda que existam penumbras. (FIG.4) Já no Ponto D, a opacidade da cobertura cria sombras mais intensas. (FIG.5)

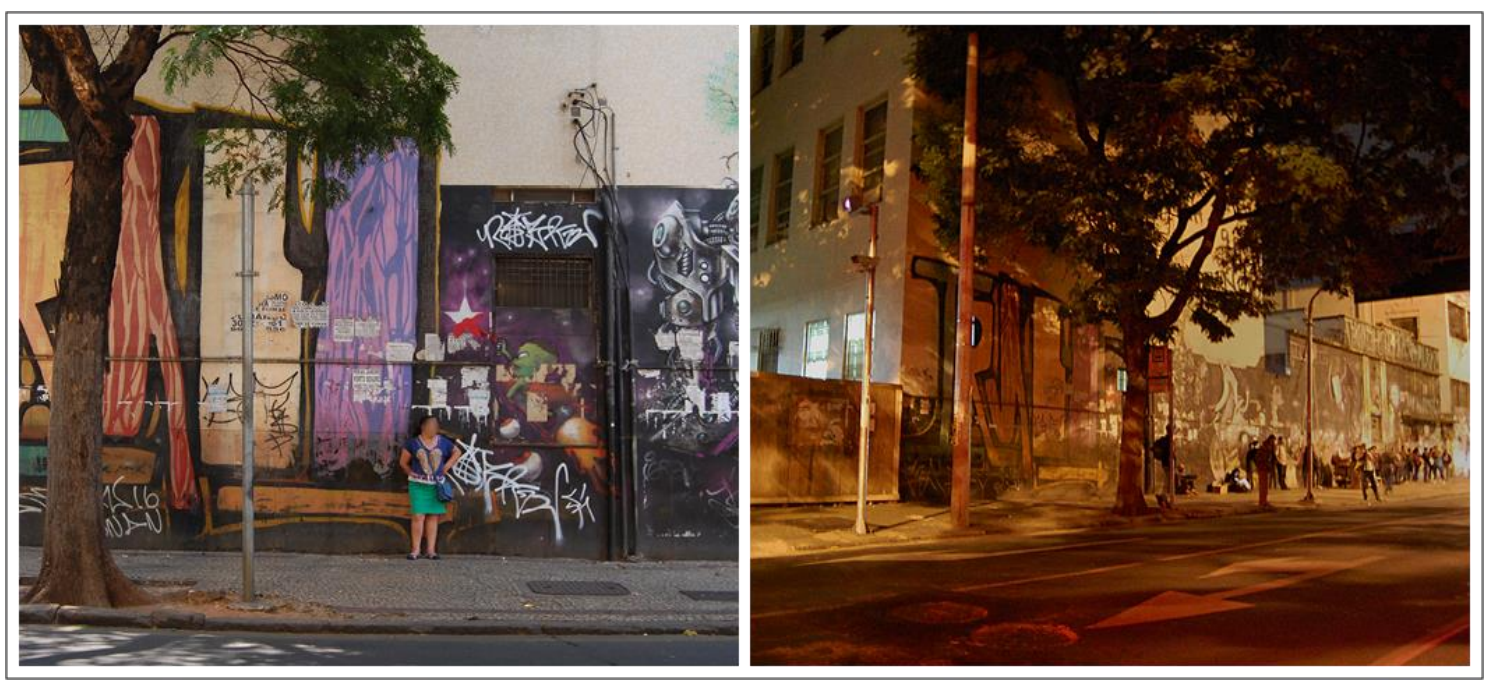

Figura 2: Ponto A.

Fonte: As autoras. 


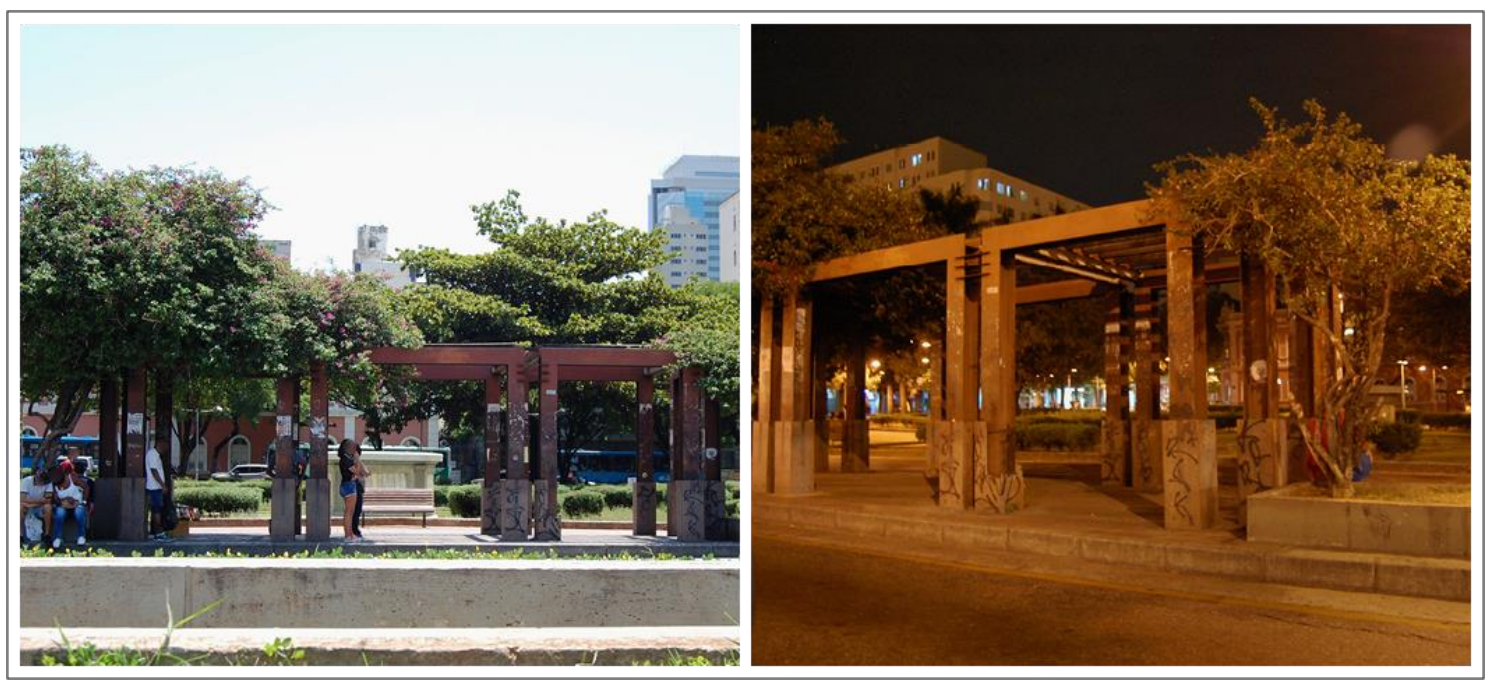

Figura 3: Ponto B.

Fonte: As autoras.

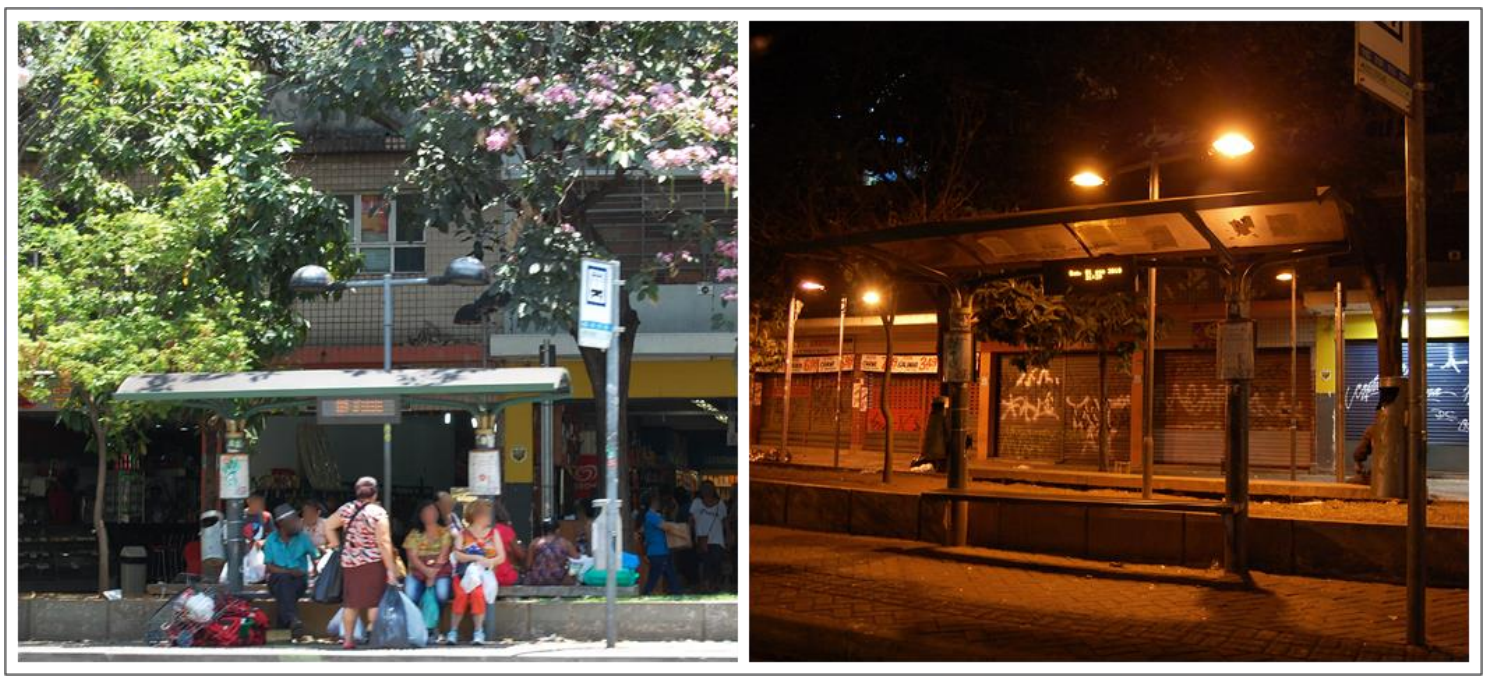

Figura 4: Ponto $C$

Fonte: As autoras.

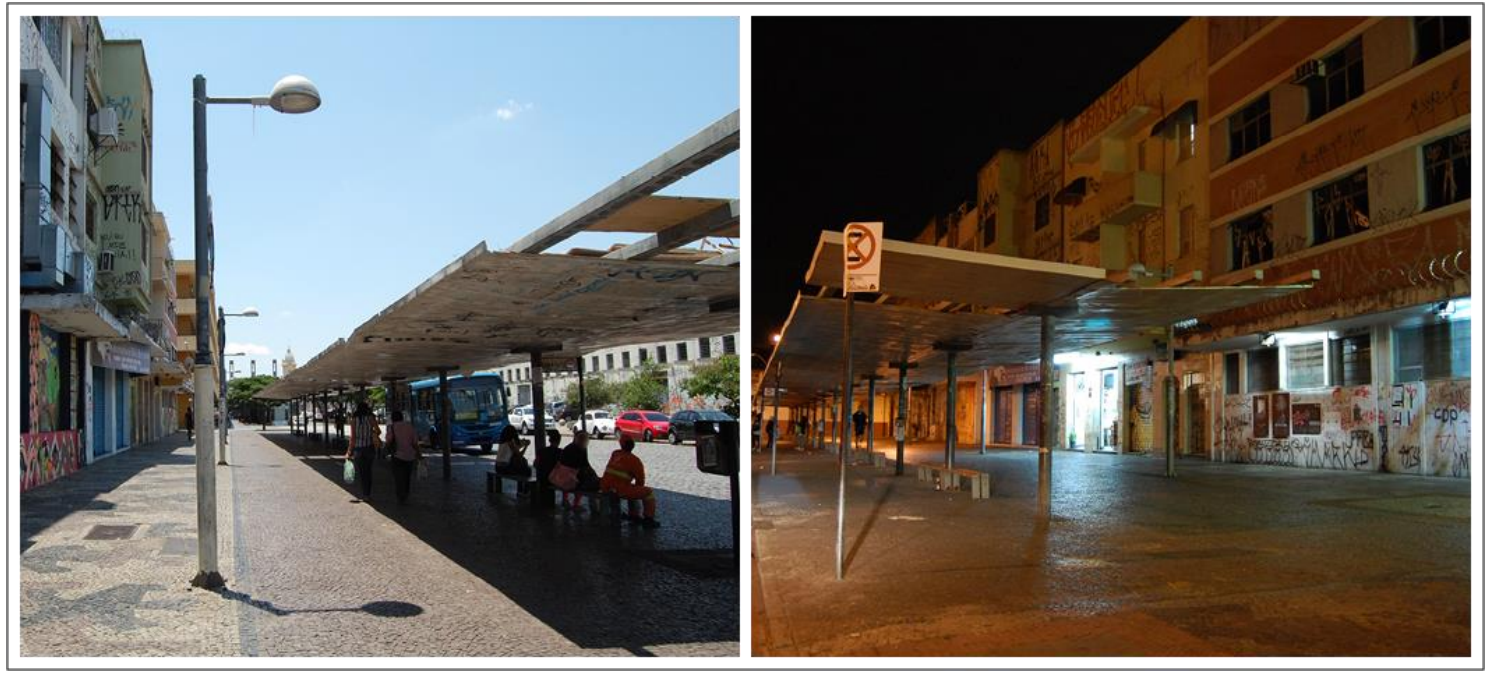

Figura 5: Ponto D.

Fonte: As autoras. 
Positivamente, as luminárias das regiões estudadas são do tipo cut-off, isto é, direcionam a luz para baixo, reduzindo a poluição luminosa e o desperdício de energia. Entretanto, a integração deficiente com a vegetação e, em alguns casos, com a estrutura do ponto criou, em todos os espaços analisados, fortes áreas de penumbra, acentuando a percepção de insegurança nos locais.

Segundo as Normas de Distribuição da CEMIG (2012), as luminárias da praça e das calçadas mencionadas possuem lâmpadas de vapor metálico enquanto das avenidas e ruas, de vapor de sódio. A temperatura de cor da luz na região dos quatro pontos é baixa, isto é, as lâmpadas emitem luz de tonalidade amarelada.

\section{Resultados dos formulários}

Os formulários foram aplicados entre os dias 6 e 28 de setembro de 2018, com 104 mulheres nos quatro pontos de ônibus investigados. O total de participantes nos Pontos A, B, C e D foi de, respectivamente, 34, 24, 26 e 20 mulheres. Segundo os resultados, 86,5\% das mulheres sentem-se inseguras nos pontos, sendo o A percebido como o menos seguro e, como mais seguro, o C. (FIG.6)

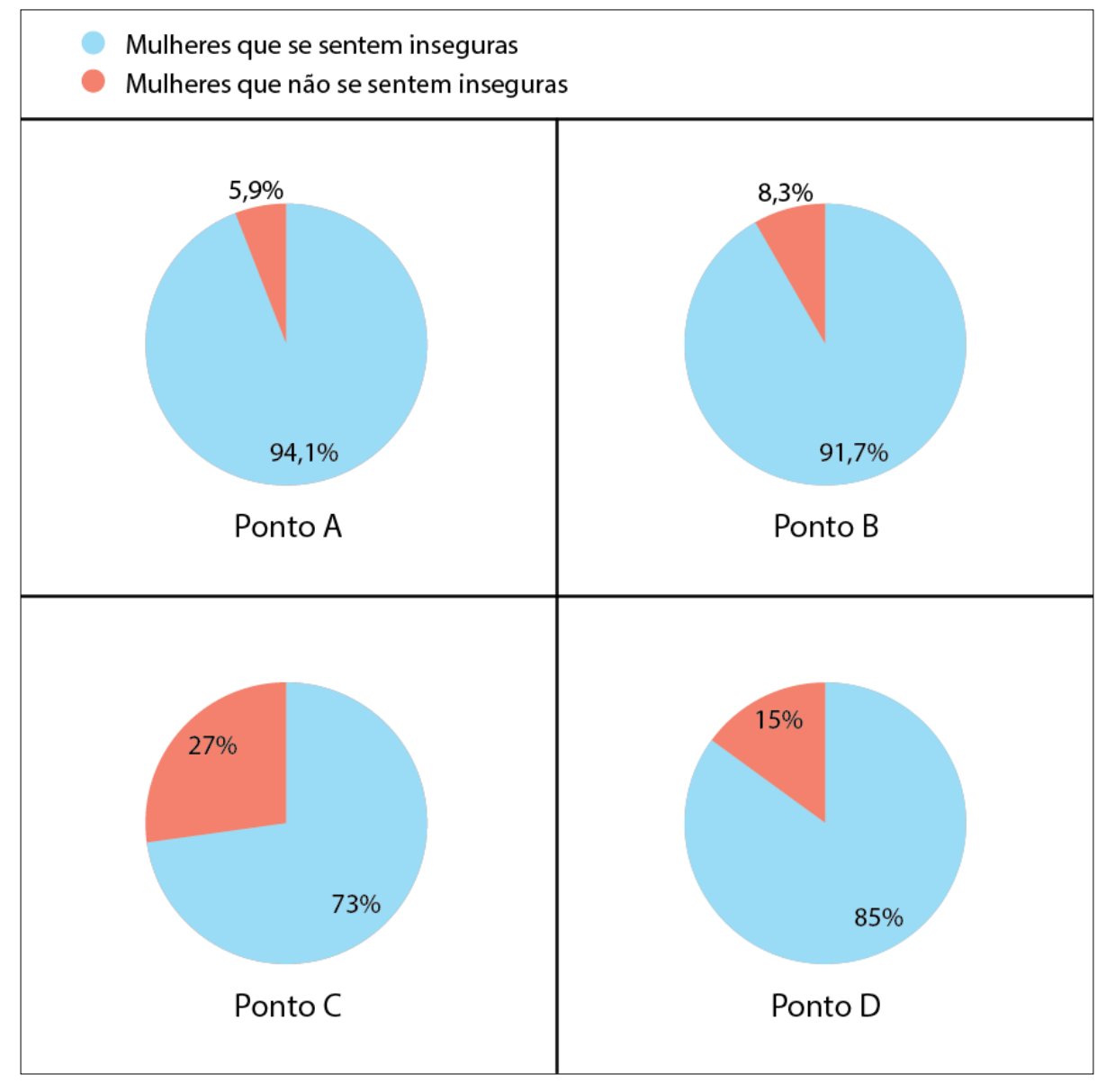

Figura 6: Taxa de sensação de insegurança nos pontos de ônibus.

Fonte: As autoras. 
No Ponto A, os formulários revelaram como principais motivos da sensação de insegurança a falta de estabelecimentos comerciais e a má iluminação (FIG.7). A falta de policiamento e a demora dos ônibus também foram apontados como fatores críticos. Algumas mulheres relataram que preferem se deslocar a outros pontos próximos, com linhas de ônibus menos acessíveis, a permanecer neste ponto.

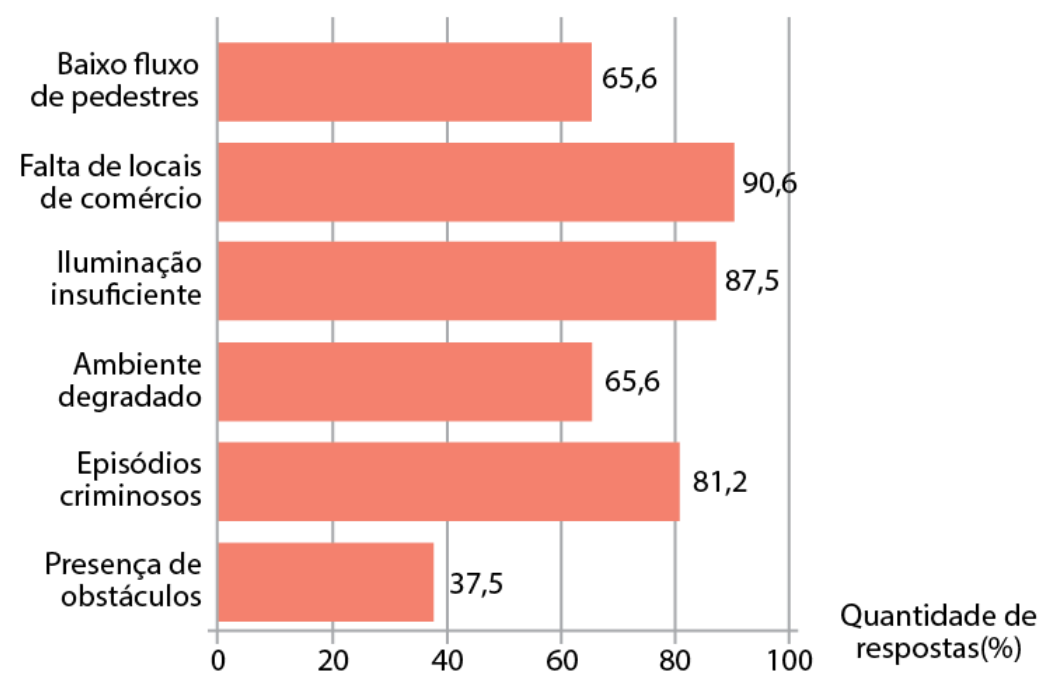

Figura 7: Motivos para insegurança no Ponto A.

Fonte: As autoras.

No Ponto $\mathrm{B}$, as entrevistadas perceberam a má iluminação e a ocorrência de eventos criminosos como principais causas da sensação de insegurança (FIG.8). Muitas relataram casos de crimes de assédio na região.

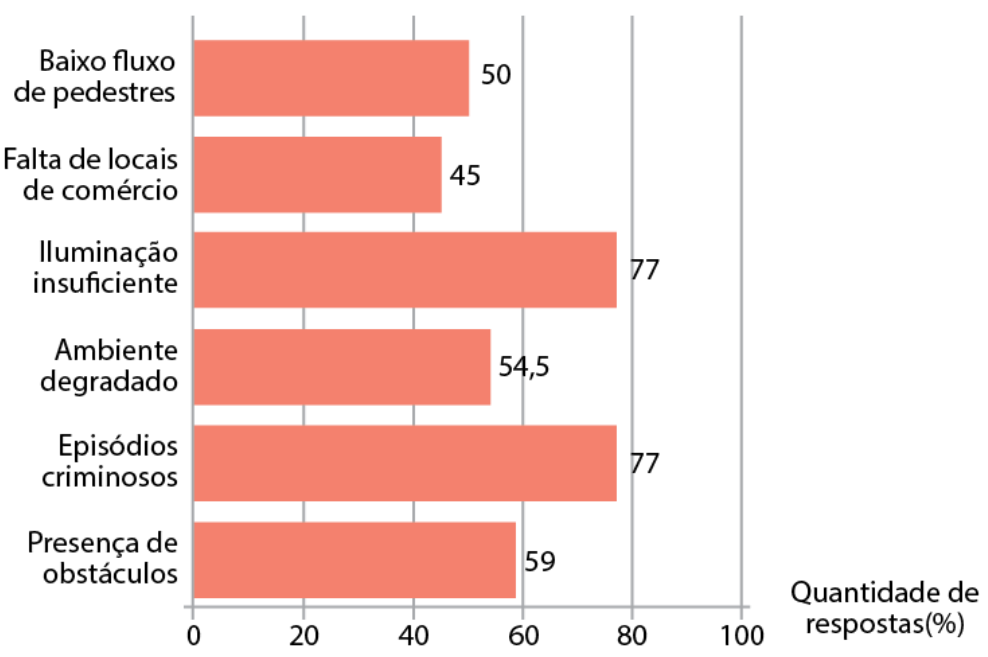

Figura 8: Motivos para insegurança no Ponto B. Fonte: As autoras 
No Ponto C, o principal motivo apontado como causa da insegurança é a ocorrência de eventos criminosos na região, como assaltos, casos de assédio e usuários de drogas ilícitas (FIG.9). O menos citado - falta de estabelecimentos comerciais - deve-se à presença de comércios no entorno do ponto, alguns funcionando até às $23 \mathrm{hrs}$. Este ponto é percebido como o mais seguro entre os quatro, corroborando a análise espacial realizada. Entretanto, para as entrevistadas, o fluxo de pedestres na região não é significativo da forma como considerada pela análise espacial.

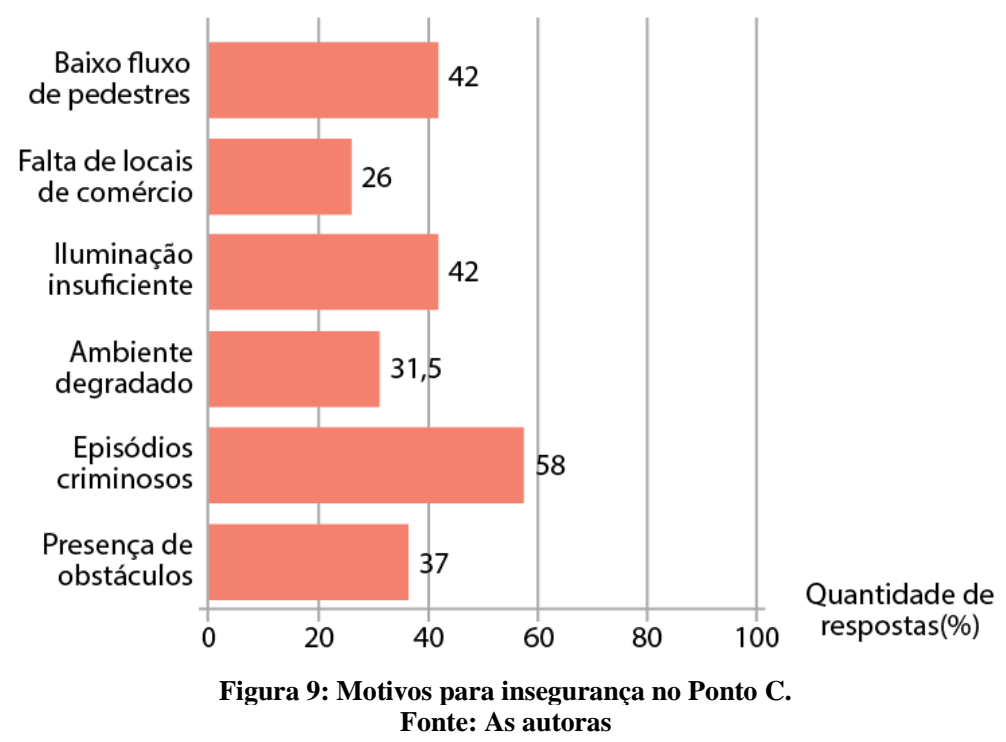

No Ponto D, os principais motivos da sensação de insegurança foram a degradação da região e a ocorrência de eventos criminosos. (FIG.10) A falta de estabelecimentos comerciais foi pouco citada, revelando que o fluxo de pedestres na região é considerado significativo. Entretanto, algumas mulheres comentaram sobre a redução do movimento de pedestres e de indivíduos à espera dos ônibus após $23 \mathrm{hrs}$, quando preferem se deslocar para outro ponto próximo, na Avenida dos Andradas, onde há maior fluxo de veículos. Ademais, a presença de penumbras é atenuada pela iluminação do entorno, segundo as entrevistadas.

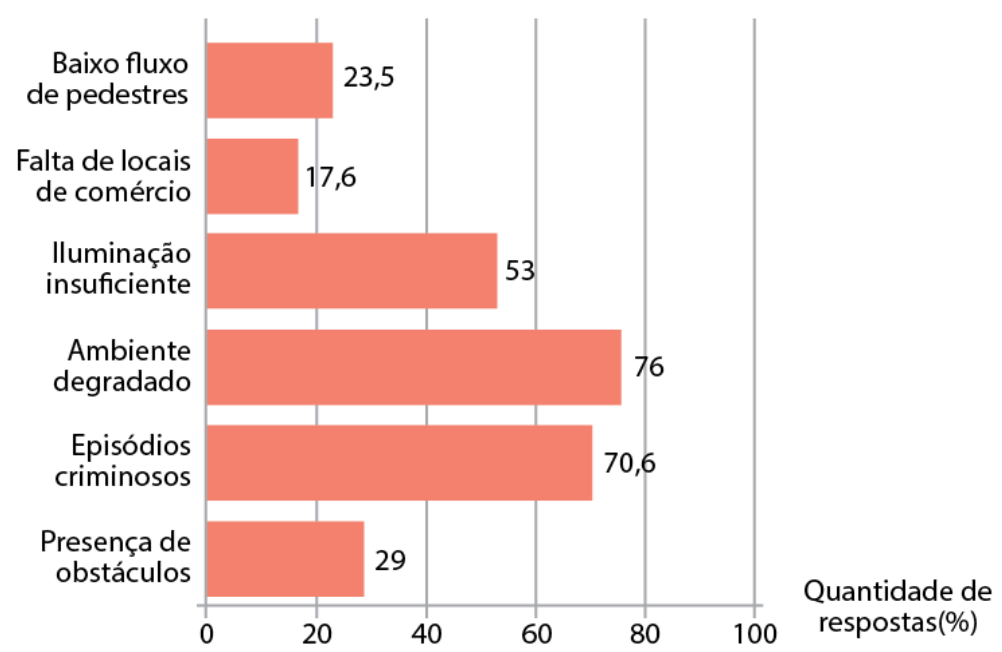

Figura 10: Motivos para insegurança no Ponto D. Fonte: As autoras 
Em geral, as respostas dos formulários confirmam as análises espaciais realizadas. A iluminação deficiente ou mal posicionada, a ocorrência de episódios criminosos e o baixo movimento no entorno, dado pela falta de comércio ou reduzida movimentação de pedestres, foram destaques nos quatro locais analisados.

Como sugestões de possíveis melhorias, as participantes sinalizaram a criação de estratégias que aumentassem o fluxo de pessoas nas ruas, ou seja, soluções urbanas que estimulassem a ocupação dos espaços pelos cidadãos (comércios, utilização de prédios ociosos, aumento no número de pontos de ônibus), aumento no policiamento e melhorias nas estruturas dos pontos, como coberturas e bancos. Entretanto, dentre todas as sugestões apresentadas nos formulários, apenas as relativas à iluminação (incluindo sugestões sobre podas de árvores e instalações de luzes específicas para os pontos) apareceram em todos os locais estudados (A, B, C e D), reforçando as ideias apresentadas pela revisão bibliográfica de que a iluminação está estreitamente relacionada à sensação de segurança das mulheres nos espaços urbanos.

\section{Discussão dos resultados}

A investigação no contexto nacional permitiu identificar dois fatores fundamentais na construção da percepção de segurança das mulheres nos pontos de ônibus: a presença de pessoas e a iluminação. $O$ primeiro fator está relacionado à criação de oportunidades de vigilância natural, principalmente pela presença de comércio e pelo uso informal da cidade. Constatou-se que a taxa de sensação de segurança das mulheres é maior onde há maior número de estabelecimentos comerciais. Ademais, a menor taxa de sensação de segurança está associada a locais onde concentram-se edificações em estado ocioso.

Referente à iluminação, as penumbras, resultantes da integração deficiente entre luminárias públicas e vegetação ou estrutura do ponto, são um fator negativo nos locais investigados. As sombras marcantes e o forte contraste entre zonas claras e escuras geram desconforto e dificuldade de adaptação visual, aumentando a sensação de insegurança. Sensação esta minimizada quando a iluminação na região é satisfatória, mesmo em presença de penumbras na área interna do ponto de ônibus. Essa condição estaria relacionada à visibilidade condicionada pela iluminação, possibilitando o aumento da percepção de segurança e a melhora de resposta de um indivíduo sobre potenciais riscos (LOEWEN et al., 1993) (HAANS; KORT, 2012).

Acrescenta-se que, em uma região com grande fluxo de pedestres, a iluminação torna-se coadjuvante na construção da percepção de segurança das mulheres nos pontos. Entretanto, ela pode estimular a apropriação e ocupação de uma área por pedestres e por estabelecimentos comerciais pelo fator de bem-estar (FARRINGTON; WELSH, 2002).

Ressalta-se que este estudo reconhece a relevância de outros fatores no contexto investigado e as limitações da iluminação na construção da percepção de segurança das mulheres. Aos principais fatores espaciais sinalizados, somam-se outras formas de segurança pública, como o incremento no policiamento e a instalação de câmeras de vigilância ligadas à rede de monitoramento da cidade, ampliando o período de vigilância. 
É relevante compreender que os pontos de ônibus estão inseridos no contexto da cidade, sendo necessário considerá-los de forma conjunta aos outros elementos urbanos a partir da criação de um Plano Diretor específico de iluminação urbana. O objetivo desse documento seria planejar a iluminação dos diversos elementos urbanos considerando as imediações e o contexto em que estão inseridos. Entende-se que, ao analisar os pontos de ônibus em conjunto com outros fatores do contexto urbano, a abordagem deverá considerar as particularidades do local de implantação.

\section{Considerações finais}

Este artigo demonstrou que o espaço urbano pode tanto favorecer uma relação de medo entre mulheres e cidade, quanto proporcionar-lhes experiências mais positivas. Por fim, percebe-se que é necessário planejar as cidades não apenas segundo princípios técnicos e quantitativos, mas também a partir das percepções dos usuários. Portanto, destaca-se a importância da participação coletiva nas decisões sobre a cidade e suas transformações, de forma a garantir a segurança, o acesso e a ocupação igualitária dos espaços urbanos. Espera-se que este estudo possibilite o desdobramento de futuras investigações na área da iluminação. Apesar de não determinar comportamentos, a iluminação possui grande importância sobre a percepção espacial dos indivíduos e, portanto, sobre a relação e interação entre homem-ambiente.

\section{Referências}

ACTIONAID. Brasil lidera assédio de mulheres em espaço público. ActionAid, Brasil, 2016. Disponível em: <http://actionaid.org.br/noticia/brasil-lidera-assedio-de-mulheres-emespaco-publico/>. Acesso: 19abr.2018.

ATKINS, S., HUSAIN, S., STOREY, A. The influence of street lighting on crime and fear of crime. Crime Prevention Unit Paper, London, 1991. n.28.

BOER, R., de VRIES, J. The right to the city as a tool for urban social movements: the case of Barceloneta. The 4th International Conference of the International Forum on Urbanism. Amsterdam, 2009.

BOWMAN, C. Street harassment and the informal ghettoization of women. Cornell Law Faculty Publications. Cornel Law School, 1993.

Companhia Energética de Minas Gerais. Manual de distribuição: projetos de iluminação pública. Belo Horizonte, 2012.

FARRINGTON, D., WELSH, B. Effects of improved street lighting on crime: a systematic review. Home Office Research. London, 2002. n.251.

FISHER, B., NASAR, J. Fear of crime in relation to three exterior site features: prospect, refuge and escape. Environment and Behavior, SAGE, 1992.

GORDON, G. Interior lighting for designers. Canada. John Wiley \& Sons, 2003.

HAANS, A., KORT, Y. Light distribution in dynamic street lighting: two experimental studies on its effects on perceived safety, prospect, concealment, and escape. Journal of Environmental Psychology. Eindhoven University of Technology, Netherlands, jun.2012. 
INSTITUTO DE POLÍTICAS DE TRANSPORTE E DESENVOLVIMENTO (ITDP). O acesso de mulheres e crianças à cidade. ITDP, jan.2018. Disponível em: <http://2rps5v3y8o843iokettbxnya.wpengine.netdna-cdn.com/wpcontent/uploads/2018/01/ITDP-Brasil-_-O-Acesso-de-Mulheres-e-Criancas-a-Cidade-_JAN-2018.pdf>. Acesso: 19abr.2018.

JACOBS, J. Morte e vida de grandes cidades. São Paulo: Martins Fontes, 2000.

KEANE, C. Evaluating the influence of fear of crime as an environmental mobility restrictor on women's routine activities. Environment and Behavior. vol.30, n.1. SAGE, 1998.

KRUG, E. G. et al. World report on violence and health. Ch.6, Sexual Violence. Geneva, World Health Organization, 2002. Disponível em: <http://www.who.int/violence_injury_prevention/violence/global_campaign/en/chap6.pdf>. Acesso: 25abr.2018.

LOEWEN, L., STEEL, G. D., SUEDFELD, P. Perceived safety from crime in the urban environment. Journal of Environmental Psychology. University of British Columbia, Canada, 1993.

NOSSA BH. Sistema de indicadores. Movimento Nossa BH. Disponível em: <http://www.nossabh.org.br/indicadores/fontes.html\#>. Acesso: 19abr.2018.

PERKINS, D., ABRAHAM, R., TAYLOR, R. The physical environment of street crime: defensible space, territoriality and incivilities. Journal of Environmental Psychology, n.13, p.29-49. Academic Press, 1993.

RAPOPORT, A. Human aspects of urban form: towards a man-environment approach to urban form and design. University of Wisconsin-Milwaukee: Pergamon, 1977.

WILSON, J., KELLING, G. Broken windows: the police and neighborhood safety. The Atlantic Online, 1982. Disponível em: <https://www.theatlantic.com/magazine/archive/1982/03/broken-windows/304465/>

\section{Sobre os autores}

\section{Victória Loureiro Cardoso}

Graduada em Design de Ambientes pela UEMG, com interesse em pesquisas nas áreas de design, iluminação pública, percepção espacial, gênero e cidades.

vloureirocar@gmail.com

\section{Sílvia de Alencar Rennó}

Mestre em Arquitetura pela UFMG, Especialista em Gestão do Design pela UEMG e Graduada em Arquitetura e Urbanismo pelo Centro Universitário Izabela Hendrix. Professora e Pesquisadora na Escola de Design da UEMG com atuação e pesquisa nas áreas de arquitetura, teoria da arquitetura e do design, projetos e iluminação.

silvia.renno@uemg.br 